\title{
Utilização de tecnologias de informação e comunicação em uma cooperativa agroindustrial em Concórdia, Santa Catarina
}

\section{Use of information and communication technologies in an agroindustrial cooperative in Concórdia, Santa Catarina}

\author{
Marcos Roberto Pires Gregolin ${ }^{1}$; Graciela Caroline Gregolin ${ }^{2}$; Caroline Monique Tietz Soares ${ }^{3}$; Adriana Maria de Grandi ${ }^{4}$
}

Resumo: A sustentabilidade das propriedades de agricultura familiar passa por diversos estágios, e é possível referenciar a diversificação dos cultivos e a agroindustrialização de produtos primários como dois deles. Na medida em que o agricultor deixa de apenas entregar sua produção primária a outro agente da cadeia produtiva, ele passa a se deparar com desafios e barreiras que outrora não conhecia. As cooperativas de agricultores familiares apresentam-se como uma alternativa eficiente para auxiliar os produtores na superação dessas dificuldades. Nesse contexto as Tecnologias de Informação e Comunicação (TIC's) surgem como ferramentas e aplicações para, criativamente, encarar um dos principais gargalos da agroindustrialização familiar: a comercialização. Objetivou-se contextualizar os limites e potencialidades da utilização de TIC's na gestão organizacional, marketing, comunicação e comercialização na Cooperativa de Produção Agroindustrial Familiar de Concórdia (COPAFAC), localizada em Concórdia, Santa Catarina. Para tanto, realizou-se um estudo de caso de caráter exploratório e qualitativo, por meio de observação ativa e de um questionário semiestruturado. A cooperativa em questão se utilizava de TIC's, objetivando desempenhar tarefas do dia a dia de maneira ágil e eficaz. Entretanto, nas agroindústrias cooperadas, observou-se uma maior fragilidade dos agricultores, especialmente pela dependência dos filhos na utilização das TIC's, assim como pela falta de empenho, dedicação e hábito dos mesmos. Os gestores da cooperativa, apesar das dificuldades enfrentadas, têm se esforçado para aprimorar o uso das TIC's, bem como para ampliar a utilização destas ferramentas por parte de seus cooperados, visando não só uma melhor organização, mas também diminuição dos custos e o aumento na comercialização dos produtos.

Palavras-chave: Agricultura familiar; Comercialização; Gestão; Organização.

\begin{abstract}
The sustainability of family farming properties goes through several stages, and can refer to the diversification of crops and agro-industrialization of primary products as two of them. To the extent that the farmer gets only deliver primary production to another agent in the production chain, it happens to come across challenges and barriers that previously did not know. Cooperatives of farmers present as an efficient alternative to assist producers in overcoming these difficulties. In this context it has been the Information and Communication Technologies (ICTs) as tools and applications to creatively face one of the main bottlenecks of family agroindustrialization: marketing. The objective of this study was to contextualize the limits and potential of the use of ICT in organizational management, marketing, communication and marketing in a cooperative. Therefore, there was a case study of exploratory and qualitative, through participant observation and semi-structured questionnaire. The cooperative in question was using ICTs aiming perform tasks of daily life in a fast and effective way. However, the cooperative agribusinesses, there was a greater fragility of farmers, especially the dependence of children for the use of ICT, lack of commitment, dedication and habit. The managers of the cooperative have endeavored to improve the use of ICT as well as to expand the use of these tools by their members, despite the difficulties faced, aiming not only better organization, but also reduced costs and increased marketing of the products.
\end{abstract}

Key words: Family farming; Commercialization; Management; Organization.

\footnotetext{
*Autor para correspondência

Recebido para publicação em 17/05/2016; aprovado em 10/06/2017

${ }^{1}$ Graduando em Gestão de Cooperativas, Bacharel em Comunicação Social, Mestre em Desenvolvimento Rural Sustentável, Doutorando em Extensão Rural pela Universidade Federal de Santa Maria. E-mail: marcosgregolin@ yahoo.com.br.

${ }^{2}$ Nutricionista, Mestre em Desenvolvimento Rural Sustentável. Professora do Curso de Nutrição da Faculdade de Pato Branco. E-mail: gracigregolin@hotmail.com.

${ }^{3}$ Graduada em Tecnologia em Biocombustíveis. Mestre e Doutoranda em Desenvolvimento Rural Sustentável Universidade Estadual do Oeste do Paraná. Email: carol.tietz@hotmail.com.

${ }^{4}$ Graduada, Mestre e Doutora em Engenharia Agrícola. Professora do Programa de Pós Graduação em Desenvolvimento Rural Sustentável da Universidade Estadual do Oeste do Paraná, Marechal Cândido Rondon, Paraná. E-mail: adrianadegrandi@gmail.com.
} 


\section{INTRODUÇÃO}

Parte da agricultura, nos últimos anos, restringiu-se à prática de monoculturas extensivas, na qual as propriedades, desde familiares até latifundiárias, tornaram-se totalmente dependente de um sistema que incumbe ao meio rural um papel excessivamente produtivista, reduzindo assim os ativos rurais e também a utilização da mão de obra familiar. Entretanto, é crescente a busca por novas alternativas na tentativa de conferir ao espaço rural uma diversidade de valores e funções, uma vez que este deve gerar não apenas renda, mas qualidade de vida à sua população como um todo (WESZ JUNIOR et al., 2006).

Nessa perspectiva, a agricultura familiar vem assumindo um papel de destaque nas discussões que buscam alternativas para o desenvolvimento rural sustentável. O desenvolvimento rural, que não se restringe somente ao agrícola, tem despertado atenção de vários segmentos da sociedade. Assim, a agroindustrialização é reconhecida há décadas como uma atividade potencialmente diversificadora, estratégica e competitiva, pois permite, dentre outras, o emprego da mão de obra familiar, a pluriatividade da propriedade e a flexibilidade econômica, uma vez que se afasta dos modelos impregnados de dependência, comum nos monocultivos, principalmente de commodities, fortemente explorados e engessados no contexto de mercado globalizado (TESTA et al., 1996).

Outrossim, a agregação de valor aos produtos, podendo ser realizada por intermédio da agroindustrialização, permite preservar hábitos e costumes das unidades familiares de produção, respeitando a vocação familiar e os conhecimentos passados de geração para geração. Além disso, cada vez mais os produtos agroindustrializados se fazem presentes na alimentação de uma parcela significativa da população. O aumento da participação destes produtos oriundos da agricultura familiar na mesa da população deve-se, principalmente, pelo fato de que a proximidade entre produtor e consumidor pode reduzir, consideravelmente, os custos com logística e também a participação de atravessadores e intermediários (WESZ JUNIOR; TRENTIN, 2004).

$\mathrm{Na}$ medida em que o agricultor deixa de somente produzir a matéria prima, a qual outrora era comercializada a outros para o processamento, ele precisa assumir também novas posturas e atuar em demais elos da cadeia produtiva, fazendo seu produto chegar até o consumidor final. É nesse momento que o cooperativismo se apresenta como uma solução capaz de apoiar os agricultores, como por exemplo, auxiliando na qualificação da gestão da agroindústria e aumentando a probabilidade de inserção dos produtos no mercado, possibilitando assim um maior êxito na comercialização de sua produção (BRASIL, 2003).

As cooperativas da agricultura familiar são organizações que surgem com o objetivo de auxiliar os seus cooperados a desempenhar alguma ação dentro da cadeia produtiva, seja na compra de insumos, no processamento e beneficiamento de matérias primas, na regularização sanitária ou ambiental, na busca por crédito ou na comercialização dos produtos. Esses objetivos estão diretamente ligados ao cotidiano de seus cooperados e às dificuldades que cada um deles enfrentaria sozinho, que passam então a ser compartilhadas com o todo a partir do momento em que se integram a uma cooperativa (GREGOLIN, 2015).
As propriedades dos agricultores familiares podem ser comparadas com pequenas empresas familiares, nas quais, de acordo com Moreira Junior (1999), a mão de obra, a gestão e a posse estão sob a égide dos membros da família. Nas cooperativas de agricultores familiares essa situação se repete, sendo geralmente os próprios agricultores, integrantes do quadro social, que exercem esses papéis.

Estudos revelam que $80 \%$ das pequenas empresas familiares entram em falência em menos de cinco anos (VELOSO, 2000) e uma das alternativas para que isso não aconteça é apostar no empreendedorismo. A mesma aposta é válida para as cooperativas de agricultores familiares, pois segundo Dornelas (2003), administrar um negócio de maneira empreendedora subentende fazer algo novo e focar na busca de novas oportunidades, utilizando os recursos disponíveis de forma criativa e inovadora.

Frente a isto, têm-se as Tecnologias de Informação e Comunicação (TIC's), as quais fazem referência a procedimentos, métodos e equipamentos utilizados para processar e propagandear informações. As TIC's sistematizam as informações e agilizam a sua divulgação, por meio de imagens, textos, áudios, vídeos e outros (CORREIA; SANTOS, 2013). De acordo com Ramos (2008) as TIC's podem ser classificadas em três grupos, controle e automação, computação e comunicação, sendo que nelas, se encontram diversas ferramentas e aplicações, as quais revolucionaram o cotidiano das pessoas e organizações.

Diante destas considerações, objetivou-se contextualizar os limites e potencialidades da utilização de TIC's na gestão organizacional, marketing, comunicação e comercialização na Cooperativa de Produção Agroindustrial Familiar de Concórdia (COPAFAC) localizada no Território Alto Uruguai Catarinense, Santa Catarina.

\section{MATERIAL E MÉTODOS}

A pesquisa foi realizada em uma Cooperativa de Produção Agroindustrial Familiar do Alto Uruguai Catarinense, localizada no município de Concórdia, Santa Catarina e trata-se de um estudo de caso de caráter exploratório e qualitativo. Segundo Yin (2010) o estudo de caso é um método utilizado quando se almeja compreender intimamente um evento da vida real, o qual não pode ser isolado do meio em que ele se insere.

O presente estudo foi definido como exploratório, levando-se em consideração que o objetivo foi propiciar uma visão geral do fenômeno estudado, possibilitando uma aproximação com o mesmo. Além disso, segundo Gil (2008) este tipo de pesquisa comumente abrange levantamento bibliográfico e documental, entrevistas não padronizadas e estudos de caso.

A pesquisa de abordagem qualitativa é realizada quando se busca conhecer aspectos particulares de um fato em questão. "Ela se preocupa, nas ciências sociais, com um nível de realidade que não pode ser quantificado. Ou seja, ela trabalha com o universo de significados, motivos, aspirações, crenças, valores e atitudes, o que corresponde a um espaço mais profundo das relações, dos processos e dos fenômenos que não podem ser reduzidos à operacionalização de variáveis" (MINAYO, 2009, p. 21).

Como método para coleta de dados, utilizou-se uma entrevista, alicerçada em um questionário semiestruturado 
composto por 15 questões abertas, semiabertas e de múltipla escolha, cuja aplicação foi realizada junto à presidente e à secretária da cooperativa em meados de julho de 2014. A escolha das respondentes levou em consideração o atendimento ao objetivo deste estudo bem como o entendimento de quais indivíduos sociais têm uma vinculação mais significativa para o problema a ser investigado (MINAYO, 2002, p. 48). Vale salientar que as mesmas assinaram um Termo de Consentimento Livre e Esclarecido, permitindo a utilização e publicação das informações levantadas para fins científicos.

Também foi utilizada a técnica denominada observação participante, a qual se baseia na ação do pesquisador no cotidiano da comunidade, grupo ou situação estudada (GIL, 2008). Esta observação se deu no escopo do projeto de ATER "Mais Gestão", por meio de visitas realizada por dois dos autores no período de Abril de 2013 a Janeiro de 2016.

Para subsidiar o desenvolvimento do trabalho, realizouse uma pesquisa bibliográfica nas bases de dados Scielo, ScienseDirect, Google Scholar, entre outras. As principais palavras-chave utilizadas para a busca foram "agricultura familiar", "agroindustrialização" e "tecnologia de informação".

\section{Cooperativa de Produção Agroindustrial Familiar de Concórdia}

A cooperativa localiza-se no município de Concórdia (SC), situado na microrregião de Concórdia, região Oeste Catarinense. É a segunda maior cidade da região, precedida por Chapecó. Dista aproximadamente $450 \mathrm{~km}$ da capital Florianópolis. De acordo com os dados do IBGE (2010), o município conta com 68.621 habitantes, e possui uma taxa de crescimento populacional de $2,91 \%$, o que estimou para o ano de 2013 uma população de 71.499 mil habitantes. Do total de habitantes de 2010, verificou-se que aproximadamente $80 \%$ vivem em área urbana, e os outros $20 \%$ em área rural.

No município de Concórdia, assim como na maioria dos municípios da região do Alto Uruguai, é expressivo o número de agroindústrias familiares, as quais são consideradas como uma das fundamentais alternativas de geração de renda para os agricultores familiares locais. Vale ressaltar, que o Alto Uruguai Catarinense compreende mais de 100 agroindústrias familiares organizadas em cooperativas.

A história da cooperativa em estudo inicia-se em 1998, quando os atores locais do Alto Uruguai em conjunto com a agricultura familiar auto desafiaram-se a implantar, na condição de projeto piloto (Projeto de Agroindústrias Associativas dos Agricultores Familiares do Oeste Catarinense financiado pelo - PRONAF Agroindústria), uma rede de empreendimentos da agricultura familiar, administrados pelos próprios agricultores, visando à transformação e o beneficiamento dos produtos agrícolas, assim como a produção de bens e serviços, de maneira a gerar oportunidades de trabalho e renda aos produtores locais.

No entanto, por conta de algumas experiências vivenciadas na época, percebeu-se certa dificuldade em viabilizar de forma isolada estas agroindústrias de pequeno porte. Neste aspecto, a alternativa foi construir um arcabouço de comum apoio entre estes empreendimentos. Para tanto, em 12 de novembro de 1999, fundou-se a COPAFAC, um importante meio de organização social e inclusão da agricultura familiar, permitindo o acesso aos mercados de modo solidário, aberto e participativo.
A COPAFAC está sediada na Central de Comercialização dos Produtos da Agricultura Familiar - Casa do Produtor, juntamente com a Central das Cooperativas de Agricultura Familiar (CECAF). Atualmente, conta com 10 agroindústrias familiares, dedicadas ao processamento e beneficiamento de matérias primas produzidas principalmente pelos 364 cooperados. Destes, 259 são agricultores familiares, reconhecidos pela Secretaria de Agricultura Familiar - SAF. Os principais produtos comercializados são: i) olerícolas: beterraba, repolho e alface; ii) frutas: laranja e tangerina; iii) origem animal: ovos, leite in natura e salame; iv) panificados: rosca com glacê e biscoito colonial e v) beneficiados ou processados: aipim e doce de frutas.

Estes produtos são comercializados, primeiramente, no mercado convencional, ou seja, nos supermercados locais e diretamente ao consumidor na Casa do Produtor de Concórdia e em menor parcela, mas não menos importante, no mercado institucional, isto é, Programa de Aquisição de Alimentos (PAA) e Programa Nacional de Alimentação Escolar (PNAE).

\section{RESULTADOS E DISCUSSÃO}

As Tecnologias de Informação e Comunicação (TIC's) abordadas figuram no cenário nacional há algum tempo, contudo, a sua utilização no meio rural, sobretudo pelos agricultores familiares é algo recente e lentamente crescente em comparação com outros setores. Tendo por base os dados do IBGE, o percentual de pessoas que utilizam a internet no ramo agrícola passou de 1,8\% em 2005 para 4,6\% em 2008. No mesmo período a evolução no setor de Educação, Saúde e Serviço Social passou de $44,7 \%$ para $63,8 \%$. Sobre a telefonia móvel, constatou-se que $12,3 \%$ dos trabalhadores agrícolas utilizavam este serviço em 2005, evoluindo para $24,2 \%$ em 2008 (IBGE, 2008). Este crescimento, mesmo que inferior aos demais setores, vem contradizer determinadas teses de alguns autores, que adjetivam o meio rural como atrasado (SOUZA; BRANDENBURG, 2010), retrógrado e alheio as tecnologias, habitado por pessoas que se negam, ou são incapazes de absorver novos conhecimentos de cunho técnico (SILVA, 2012).

A utilização das tecnologias de informação e comunicação pelos agricultores familiares pode inovar processos de gestão, marketing, comunicação, organização, comercialização e outros. Em suma, como afirmam Viero e Silveira (2011), a utilização das TIC's amplia horizontes e gera expectativas.

\section{Utilização das TIC's pela Cooperativa de Produção Agroindustrial Familiar de Concórdia}

A sociedade convive estreitamente com as tecnologias de informação e comunicação, uma vez que essas assumiram certo protagonismo no atual mundo globalizado, gerando influência recíproca entre o desenvolvimento tecnológico e o progresso econômico (FELIPPI; DEPONTI; DORNELLES, 2017). No que se refere às propriedades rurais, as TIC's, além de contribuírem para a gestão destas, permitindo melhor compreensão em torno do empreendimento e produção, além de que potencializam os vínculos comunitários e permitem a comunicação entre distintas culturas e economias locais, regionais, nacionais e globais (CONCEIÇÃO, 2017b).

Observou-se que a cooperativa possui computador com acesso à internet, o qual é utilizado como ferramenta de trabalho pela presidente (39 anos) e secretária (27 anos), 
ambas com ensino superior completo. Esses membros não demonstram dificuldade em desempenhar tarefas no tocante à organização, à gestão e também na divulgação de atividades e produtos. A idade e o nível educacional podem ser fatores que apoiam a apropriação e utilização dessas ferramentas.

No que diz respeito ao uso de correio eletrônico, constatou-se que a presidente o utiliza diariamente, por mais de 4 horas. O domínio desta ferramenta possibilita à cooperativa manter uma comunicação eficaz e ágil com fornecedores, clientes, outras cooperativas, governos (local, estadual e federal) e qualquer cidadão que deseje informações a respeito da instituição e de seus produtos.

Ademais, verificou-se que a COPAFAC dispunha de um software de gestão, o qual era utilizado diariamente por aproximadamente 4 horas e, devido à preocupação dos seus gestores em tornar os processos administrativos cada vez mais profissionais e eficientes, buscou-se a substituição deste por outro que atendia melhor as necessidades da cooperativa, segundo as informantes. De acordo com Carvalho (2000), os programas de gestão são fundamentais para o sucesso de um negócio e os softwares ajudam a ganhar eficiência.

Em relação às redes sociais, a administração da cooperativa utiliza, desde janeiro de 2014, um perfil na maior rede social do mundo, o qual é atualizado uma vez por semana, sendo que as principais finalidades são o contato com outras cooperativas, clientes e cooperados e, em segundo plano, a divulgação de produtos e serviços, conforme relato das entrevistadas. $\mathrm{O}$ uso de plataformas sociais possibilita uma comunicação bastante popular, justificando plenamente a aposta das marcas em divulgarem o seu nome e imagem, enquanto aproveitam um serviço com custos reduzidos, comparativamente a outras formas de publicidade e marketing (CASEIRO; BARBOSA, 2011). Conceição (2017) discorre que, apesar do objetivo da rede social não ser a comercialização, a mesma tem se apresentado como um importante meio para o estabelecimento de relações comerciais, inclusive pelo seu grande alcance, seja ele local, regional, nacional e quiçá internacional.

As vantagens de a COPAFAC possuir um perfil na rede social foram, em ordem de importância, a troca de informações fácil e rápida, o acompanhamento de atualizações, as novas amizades/clientes e as relações empresariais, ou seja, a adoção destas tecnologias proporciona "maiores oportunidades para a geração de relacionamentos e manutenção de interação entre indivíduos" (KIMURA; BASSO; MARTIN, 2008, p. 160) situação esta totalmente favorável para a potencialização das ações da cooperativa no âmbito de seu negócio.

Com relação à troca de informações, nota-se que os gestores da cooperativa buscam, por meio da rede social, divulgar ações e mobilizar cooperados, convocando os mesmos para reuniões de discussão de canais de comercialização e também para assembleias. Ressalta-se, que no caso da comunicação interna, as publicações em rede social não devem substituir os mecanismos tradicionais e estabelecidos pela legislação cooperativista para divulgação de atos, como por exemplo, convocação de assembleia. Neste caso o preconizado pela lei $\mathrm{n}^{\circ} 5.764$ é de que a convocação seja fixada em mural de ambientes onde os cooperados circulam e também publicado em jornal de alcance local ou regional (BRASIL, 1971). Além disso, observou-se que a rede social também é utilizada como meio de disseminar mensagens de fortalecimento do cooperativismo e da agricultura familiar, demonstrando uma das grandes utilidades da rede social, a propagação de mensagens de apoio e incentivo entre seus "amigos" ou "seguidores". Por meio destas, o cooperativismo pode ser propagado e reforçado, principalmente, se os cooperados, os parceiros e o público em geral forem alvo das mensagens, em um meio que facilite divulgar seus princípios.

No que tange ao impacto proporcionado pelo uso da rede social no trabalho da cooperativa, destacou-se a maior visibilidade dos produtos, conforme relatou a presidente sobre o ato de "postar produtos e os clientes verem, solicitando informações que proporcionaram vendas". De acordo com Kimura, Basso e Martin (2008) esses novos meios de comunicação são muito relevantes, pois proporcionam interação e sedimentam vínculos, aumentam a velocidade e fomentam a "aproximação" entre os indivíduos. Este reforço nos vínculos parece influenciar positivamente nas relações comerciais da cooperativa.

Segundo Caseiro e Barbosa (2011) a utilização de uma rede social como estratégia de marketing pode permitir a criação de um canal de comunicação direto e eficaz com os clientes. Os membros das redes e simultaneamente uma larga quota de clientes, durante o seu momento particular de "navegação" pela rede social, involuntariamente acabam obtendo informações sobre os produtos. Além disso, a presença da cooperativa neste "meio" é importante para que possa conhecer melhor e entender, de modo informal e eficiente, quais as opiniões dos clientes sobre os produtos oferecidos. Estes préstimos da rede social para a cooperativa são descritos por Kimura, Basso e Martin (2008) como a possibilidade de uma "forte interação entre usuários" e que estas relações "podem constituir um novo campo de batalha para empresas de marketing" (KIMURA; BASSO; MARTIN, 2008, p.179)

Nota-se que o perfil da cooperativa constitui uma rede que conglomera mais de 800 participantes. É fato que este número pode ser ampliado, fazendo com que a ferramenta possa atingir um maior público, seja pelas mensagens comerciais, motivacionais ou de comunicação interna. Contudo, aproveitar o atual número de participantes constitui uma possibilidade para que a atual gestão possa se comunicar melhor, principalmente para promover melhores relações com a comunidade em geral, para divulgar e também comercializar os seus produtos.

Na perspectiva de ampliação do uso das redes sociais, os dirigentes da cooperativa apontam de forma positiva. Tendo a necessidade de dedicar tempo para atualizar com maior frequência os produtos, visando "[...] buscar novos mercados, adicionar mais estabelecimentos comerciais que possam revender ou consumir em mercado de maior escala".

Constatou-se também a criação de endereços de correio eletrônico para cada agricultor proprietário de agroindústria administrar, e por meio deles otimizar os processos de comunicação entre a agroindústria e a cooperativa, fornecedores e também clientes.

Todavia, no que se refere às 10 agroindústrias da COPAFAC, averiguou-se que 08 utilizavam correio eletrônico, porém de forma não significativa, não constando registros de operações importantes realizadas por meio desta ferramenta de comunicação. Com isso, revelou-se a subutilização desse recurso, tendo em vista a demora de grande parte dos agricultores gestores de unidades 
agroindustriais em retornar às solicitações enviadas por intermédio de correio eletrônico.

Salienta-se que foram elaboradas as artes dos cartões de visita possibilitando aos agricultores divulgar o seu endereço eletrônico e sua rede social, contudo, antes da impressão destes, muitas contas de e-mail e perfis não haviam sido utilizados, nesses casos, optou-se por constar no cartão os canais de comunicação da cooperativa, para que esta então possa figurar como agente nos casos em que os agricultores não fazem uso no mínimo esporádico das ferramentas.

A Figura 1 ilustra essa situação, na qual o cartão da esquerda é de um agricultor que teve facilidade em se apropriar das ferramentas e o cartão da direita é de um agricultor que não fez o uso das ferramentas propostas.

Figura 1. Exemplo de cartões dos cooperados da Cooperativa de Produção Agroindustrial Familiar de Concórdia (COPAFAC).

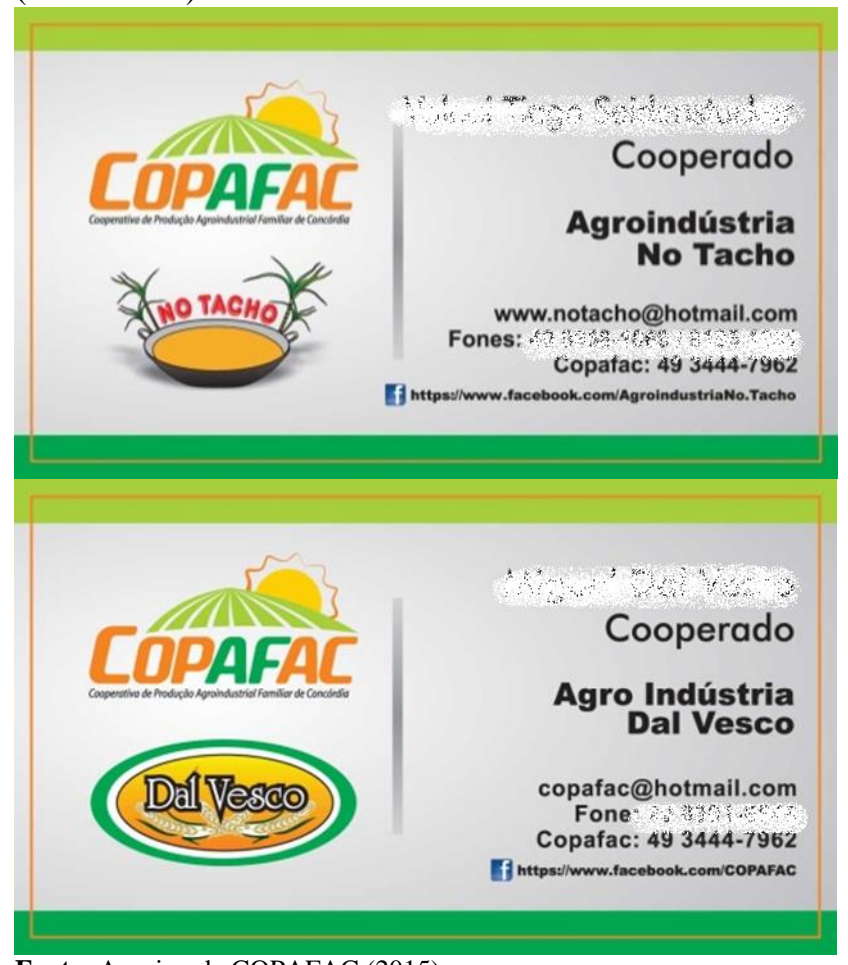

Fonte: Arquivo da COPAFAC (2015).

Constatou-se que a apropriação e o uso das TIC's pelos agricultores da COPAFAC ocorrem de maneira promissora, basicamente em dois casos: (i) agroindústrias de agricultores jovens e (ii) agroindústrias de agricultores de maior idade, mas que possuem filhos em casa.

Verificou-se ainda que das 10 agroindústrias, 07 possuíam perfil ativo na rede social. Infere-se que a criação de cada um dos perfis foi realidade com apoio de um colaborador da cooperativa e para tornar os perfis mais atrativos e dinâmicos foram fotografados os produtos e tais materiais publicados no perfil individual da agroindústria e da cooperativa.

De acordo com a OCDE - Organização para Cooperação e Desenvolvimento Econômico (2004), toda novidade implantada pelo setor produtivo, sendo por meio de pesquisas ou investimentos, é considerada como uma inovação tecnológica, cujo objetivo é aumentar a eficiência do processo ou implicar em um novo ou aprimorado produto. Isto posto, a criação de um perfil em uma rede social é uma ação simples, mas que cumpre o papel de divulgar a qualidade e aparência dos produtos, permitindo aumentar a competitividade e rentabilidade no setor, incentivando, principalmente, a permanência da família no campo.

Entretanto, a apropriação das TIC's (computador, internet, correio eletrônico e rede social) pelos cooperados da COPAFAC, agricultores gestores de unidades agroindustriais, é pequena, sendo que os principais entraves relatados foram a dependência dos filhos para a utilização, falta de empenho, de dedicação e hábito.

Contudo, essa dificuldade no uso das TIC's por parte de alguns agricultores pode ser explicada pela sobrecarga de atividades na produção das agroindústrias, resultado da falta de mão de obra, que por vezes impede a dedicação dos agricultores nos controles, na gestão, na divulgação ou na comercialização via internet. Estudo realizado por Felippi, Deponti e Dornelles (2017), em duas regiões do estado do Rio Grande do Sul, a Microrregião de Santa Cruz do Sul e a região do COREDE Vale do Caí, com famílias da agricultura familiar, constatou que o uso da TIC`s (computador, celular e internet) nessa população está relacionado, principalmente, às atividades de lazer, justificado, sobretudo, pela rara oferta de lazer no meio rural. Ainda, observou-se dificuldade dos agricultores familiares em utilizar softwares e informações de gestão.

Se esta realidade for observada de uma maneira menos detalhista, o fato de os agricultores terem computador em casa ou terem acesso à internet não os enquadraria nas estatísticas de exclusão digital, contudo, segundo Sorj e Guedes (2005) essa situação não trata de um fenômeno simples, o qual se limita ao universo dos incluídos e excluídos, mas sim de uma polaridade real, que por vezes mascara seus múltiplos aspectos.

A exclusão ou inclusão digital não pode ser mensurada unicamente pelo número de proprietários de computador ou de pessoas que possuem acesso à internet, é necessário que vários outros fatores relevantes sejam contabilizados, principalmente o tempo que o usuário tem disponível e a qualidade do acesso, os quais afetam decisivamente o uso da internet devido ao fato dessas TIC's serem dinâmicas e requererem constantes atualizações. Isso exige um investimento regular por parte dos usuários para que não fiquem obsoletos, e também depende da capacidade de leitura e interpretação da informação pelo usuário (SORJ; GUEDES, 2005).

Além disso, observa-se que no Brasil ainda são poucas as iniciativas de comercialização de produtos ou serviços pela internet, sobretudo no meio rural. A exemplo, cita-se que os grandes desafios para a expansão de tais iniciativas são os problemas de comunicação, uma vez que nem todo território nacional é coberto por telefonia, fixa ou móvel, e apenas $15 \%$ do território rural tem acesso à internet (CONCEIÇÃO, 2017a).

O uso das TIC's pode agilizar também os processos de gestão, como envio de notas e pedidos, bem como reduziria a dependência do telefone, haja vista que os cooperados nem sempre dispõem de um serviço de telefonia móvel com qualidade e que proporcione uma comunicação eficiente. No entanto, "o acesso a essas tecnologias não ocorre de maneira uniforme, oscilando conforme a presença de maior ou menor 
infraestrutura e as possibilidades financeiras de acesso à tecnologia dos usuários" (FELIPPI; DEPONTI; DORNELLES, 2017, p. 26).

Compreende-se assim ser imprescindível a presença da internet no meio rural, haja vista a gama de benefícios que está possibilita, como uma maior visibilidade dos empreendimentos, acesso a informações atualizadas, à inserção em novos e diferenciados mercados, contato com novas formas de produção, e de certa forma, uma aproximação entre produtor e consumidor (CONCEIÇÃO, 2017a).

\section{CONCLUSÕES}

Na Cooperativa de Produção Agroindustrial Familiar de Concórdia, seus dirigentes, funcionários e a maioria dos agricultores gestores de unidades agroindustriais têm se esforçado para utilizar as TIC's, especialmente, no que se refere ao uso da internet, das redes sociais e também de softwares destinados à organização e acesso às informações da cooperativa.

$\mathrm{Na}$ utilização das TIC's pela COPAFAC, as redes sociais e a ferramenta e-mail tem se prestado para o aprimoramento da gestão organizacional, comunicação, divulgação e comercialização. O Software de gestão proporciona uma melhor organização de diversos ambientes dentro da cooperativa.

Evidencia-se a necessidade de estratégias, especialmente relativa à inclusão digital de agricultores familiares, por meio de capacitações aos públicos de maior idade, a fim de permitir sua atuação de forma independente, haja vista que se constatou que as famílias de agricultores tendem a se apropriar com maior facilidade destas tecnologias nos casos onde há a presença de jovens atuantes ou no mínimo auxiliando os familiares.

\section{REFERÊNCIAS}

BRASIL. Lei n. ${ }^{\circ}$ 5.764, de 16 de dezembro de 1971. Define a Política Nacional de Cooperativismo, institui o regime jurídico das sociedades cooperativas, e dá outras providências. In:Diário Oficial da República Federativa do Brasil, Brasília, DF, 16 dez. 1971.

BRASIL. Ministério do Desenvolvimento Agrário - MDA. Referências para o desenvolvimento territorial sustentável. Apoio técnico e cooperação do Instituto Interamericano de Cooperação para a Agricultura - IICA. Série texto para discussão 04. Brasília: Conselho Nacional de Desenvolvimento Rural Sustentável - CONDRAF, Núcleo de Estudos Agrários e Desenvolvimento Rural. 2003. 36p.

CASEIRO, B.; BARBOSA, R. Empresas no Facebook: o caso da TMN e da Optimus. Internet Latent Corpus Journal, Portugal, v.2, n.1, p.6-15, 2011.

CARVAlHO, R. B. Aplicações de softwares de gestão do conhecimento: tipologia e usos. Belo Horizonte: UFMG, 2000. 143p.

CONCEIÇÃO, A. F. Do consumo à alimentação: as estratégias da comunicação e a criação de novos mercados para agricultura familiar e consumidores na sociedade contemporânea. In: Congresso da Sociedade Brasileira de Economia, Administração e Sociologia Rural, 55., 2017, Santa Maria, Anais... Santa Maria, 2017a.

CONCEIÇÃO, A. F. Utilização das TIC por agricultores familiares na gestão da propriedade rural. In: Congresso da Sociedade Brasileira de Economia, Administração e Sociologia Rural, 55., 2017, Santa Maria, Anais... Santa Maria, $2017 b$.

CORREIA, R. L.; SANTOS, J. G. A importância da Tecnologia da Informação e Comunicação (TIC) na Educação a Distância (EAD) do Ensino Superior (IES). Revista Aprendizagem em EAD, Taguatinga, v.2, 2013. Disponível em:

<http://portalrevistas.ucb.br/index.php/raead/article/viewFile/ 4399/2899>. Acesso em: 08 jun. 2014.

DORNELAS, J. C. A. Empreendedorismo corporativo: como ser um empreendedor, inovar e se diferenciar em organizações estabelecidas. Rio de Janeiro: Elsevier, 2003. $183 p$.

FELIPPI, Â. C. T.; DEPONTI, C. M.; DORNELLES, M. TICs na agricultura familiar: os usos e as apropriações em regiões do sul do brasil. Revista Brasileira de Gestão e Desenvolvimento Regional, v. 13, n. 1, 2017.

GIL, A. C. Métodos e técnicas de pesquisa social. 6.ed. São Paulo: Atlas S.A, 2008. 200p.

GREGOLIN, M. R. P. Diagnóstico de gestão em cooperativas da agricultura familiar no estado do Paraná: limites e potencialidades em um modelo solidário e democrático. 2015. 159f.Dissertação (Mestrado em Desenvolvimento Rural Sustentável) - Universidade Estadual do Oeste do Paraná Campus Marechal Cândido Rondon, Marechal Cândido Rondon, 2015.

IBGE. Instituto Brasileiro de Geografia e Estatística.Censo Demográfico 2010. 2010.

IBGE. Instituto Brasileiro de Geografia e Estatística. Pesquisa Nacional de Amostra de Domicílios. Acesso à internet e posse de telefone móvel celular para uso pessoal. 2008.

KIMURA, H.; BASSO, L. F. C.; MARTIN, D. M. L. Redes sociais e o marketing de inovações. Revista de Administração Mackenzie (Mackenzie Management Review), v. 9, n. 1, 2008.

MINAYO, M. C. de S. (org.). Pesquisa Social. Teoria, método e criatividade. Petrópolis: Vozes, 2009. 80p.

MOREIRA JUNIOR, A. L. Programas de profissionalização e sucessão: um estudo de caso em empresas familiares de pequeno porte de São Paulo. São Paulo: USP, 1999.

OCDE. Organização para Cooperação e Desenvolvimento Econômico. Manual de Oslo:Proposta de diretrizes para coleta e interpretação de dados sobre inovação tecnológica. 
Financiadora de Estudos e Projetos - FINEP: tradução português, 2004.

RAMOS, S. Tecnologias da informação e comunicação: conceitos básicos. Aveiro, 2008, 17 p.

SILVA, L. M. da. Cidades mortas: o rural como sinônimo de atraso e decadência.Revista do Programa de Pós-Graduação em Sociologia da USP, São Paulo, v.19, n.2, p.69-82, 2012.

SORJ, B.; GUEDES, L.E. Exclusão Digital: problemas conceituais, evidências empíricas e políticas públicas. Novos Estudos, n.72, p.101-117, 2005.

SOUZA, O. T.; BRANDENBURG, A. A quem pertence o espaço rural? As mudanças na relação sociedade/natureza e o surgimento da dimensão pública do espaço rural. Ambiente \& Sociedade, Campinas, v.13, n.1, p.51-64, 2010.

TESTA, V. M.; NADAL, R. de; MIOR, L. C.; BALDISSERA, I. T.; CORTINA, N. O desenvolvimento sustentável do Oeste Catarinense: proposta para discussão. Florianópolis: EPAGRI, 1996. 247p. Disponível em: <http://books.google.com/books/about/O_desenvolvimento_s ustent\%C3\%A1vel_do_Oeste.html?id=N_22AAAACAAJ $>$. Acesso em: 29 ago. 2014

VELOSO, G. Como ser empresário. Revista Jovem Empreendedor, Florianópolis: Empreendedor, p.12-16, 2000.

VIERO, V. C.; SILVEIRA, A. C. M. Apropriação de tecnologias de informação e comunicação no meio rural brasileiro. Cadernos de Ciência \& Tecnologia, Brasília, v.28, n.1, p.257-277, 2011.

WESZ JUNIOR, V. J.; TRENTIN, I. C. L. Desenvolvimento e agroindústria familiar. XLII Congresso da Sober.RevistaSociedade Brasileira de Economia e Sociologia Rural, 2004.

WESZ JUNIOR, V. J.; TRENTIN, I. C. L.; FILIPPI, E. E. A importância da agroindustrialização nas estratégias de reprodução das famílias rurais. XLIV Congresso da SOBER. Revista Sociedade Brasileira de Economia e Sociologia Rural,2006.

YIN, R. K. Estudo de caso: planejamento e métodos. Porto Alegre: Bookman, 2010. 